\title{
On the application of Fermat's interferometric principle for water-layer velocity reconstruction in OBN data
}

\author{
Yasmim Mourad Oshiro ${ }^{1}$, Francisco Carlos Lajús Junior ${ }^{1}$, Sherif Mahmoud Hanafy ${ }^{2}$, Gerard Thomas Schuster ${ }^{3}$, Carlos \\ Eduardo Theodoro ${ }^{4}$, Antonio Henrique da Fontoura Klein ${ }^{1}$ \\ ${ }^{1}$ Universidade Federal de Santa Catarina - UFSC \\ ${ }^{2}$ King Fahd University of Petroleum \& Minerals - KFUPM \\ ${ }^{3}$ King Abdullah University of Science and Technology - KAUST \\ ${ }^{4}$ Petróleo Brasileiro S.A. - PETROBRAS
}

Copyright 2021, SBGf - Sociedade Brasileira de Geofísica.

This paper was prepared for presentation at the $17^{\text {th }}$ International Congress of the Brazilian Geophysical Society, held in Rio de Janeiro, Brazil, 8 November to 11 November, 2021.

Contents of this paper are to be reviewed by the Technical Committee of the $17^{\text {th }}$ International Congress of The Brazilian Geophysical Society and do not necessarily represent any position of the SBGf, its officers or members. Electronic reproduction or storage of any part of this paper for commercial purposes without the written consent of The Brazilian Geophysical Society is prohibited.

\section{Abstract}

Knowledge of sea water velocity variations is an important issue for subsurface seismic imaging, particularly in 3D and 4D surveys where reservoir variations must be distinguished from those related to spatio-temporal water variations. A very promisingly and highly-resolved alternative to classical water velocity corrections involves the processing of small amplitude reflections observed within the water layer, during typical marine acquisitions with streamers. In this study we investigate the possibility that these very same reflections could be sensed by Ocean Bottom Nodes (OBN), thus helping the development of more detailed water velocity reconstruction for the transmitted arrivals. For that, first we conduct synthetic simulations to obtain the propagated acoustic field, enforcing our focus on its down-going components. Once such water reflections (now transmitted down to OBN location) are identified in the generated responses, some form of Fermat's interferometric redatum can be applied. It is found that such information might be helpful on the development of more detailed water velocity corrections departed strictly from their underlying signature on the transmitted arrivals.

\section{Introduction}

Vertical stratification of the ocean sound velocity is primarily generated by temperature, salinity and pressure variations, that occur simultaneously with a planetary ocean circulation and more regional mixing processes. The flow in oceans is mostly driven by wind stresses (which originates surface waves and currents), tides and buoyancy gradients, and occurs over a wide range of time and space scales, characterizing many different flow structures/patterns such as: gyres, thermohaline circulation, mesoscale eddies and the global ocean conveyor belt (WRIGHT and COLLING, 1995). Because of that, ocean studies allow a better understanding of much of the underlying influence of water circulation on the planetary weather, along with its many aspects of heat transfer, dissipation and nutritional distribution.
Additionally, proper knowledge of the sea water physical properties, and its time-varying dependence, has significant implications on $3 D / 4 D$ seismic imaging that occur specially in (ultra) deep ocean regions. The search of highly-resolved velocity models on the water layer, thus constitutes a step towards more accurate monitoring and sustainable exploration of reservoirs.

Seismic Oceanography is a relatively new field where classic multichannel seismic imaging found application to retrieve very detailed water properties distribution of ocean structures from their impedance contrast, which then are related to reflections that occur within the waterlayer (HOLBROOK and FER, 2005; FER et al., 2010). Interestingly, the possibility to identify and track reflections from interfaces between warm and cold waters along the length of a sail-line is also found in earlier work focused on water-layer correction (WOMBELL, 1996). Nonetheless, it is clear that most of the main developments on this matter were carried on by oceanographers, who saw potential on the increased horizontal resolution (compared to traditional oceanographic techniques) to explore water mass boundaries, eddies, internal waves, and thermohaline fine structure among many other oceanic phenomena. The application of Seismic Oceanography to solve water column statics was already proposed (BRIGHT et al., 2015).

The interest on a high-resolution correspondent processing for wide-angle seismic data of ocean bottom receivers is certainly not new. A current idea relies on the high amplitude seafloor multiples to recover sound velocity estimates in the water layer (GRAD et al., 2011; DUNN, 2015; LI et al., 2015), additional to averaged quantities obtained by Pressure Inverted Echo Sounder (PIES) (WANG et al., 2013). However, in this paper we venture a somewhat new possibility, that these very same waterlayer reflections could be also detected in transmitted arrivals sensed by bottom-nodes. As a feasibility study, we first carried on synthetic simulations that emphasize the down-going wave field of such water-layer reflections. Further application of Fermat's interferometric principle (SCHUSTER, 2005) is directed towards resolution improvements of the transmitted signal, throughout the redatum of identified reflections.

\section{Synthetic simulation}

The propagated acoustic field inside the water column can be assumed to be fairly represented by the varyingcoefficient wave equation (KORMANN et al., 2010), 


$$
\nabla^{2} p(\vec{x}, t)-\frac{1}{c^{2}(\vec{x})} \frac{\partial^{2}}{\partial t^{2}} p(\vec{x}, t)=s(t) \delta\left(\vec{x}-\vec{x}_{s}\right)
$$

where $p$ stands for the pressure wave-field (that varies spatially $\vec{x}$ and temporally $t$ ), $c$ represents the water sound velocity distribution, $s$ the temporally-varying source signal at a spatially-defined $\delta$ Dirac delta function. In order to eq. (1) be valid, water currents effects should be small (compared to the sound velocity), along with slight influence of density variation. Although its formal derivation generally assume constant water density $\rho$, small fluctuations are intrinsically incorporated in the relationship of sound velocity with the bulk modulus (KORMANN et al., 2010).

Regarding the applied boundary conditions in $\Omega$, pressure release conditions $\left(\left.p(\vec{x}, t)\right|_{\vec{x}=\Omega}=0\right)$ are considered. A stretched version of the simulation domain, both laterally and at the bottom part, are enforced on the velocity model showed in Figure 1. For the surface region, this condition (or similarly $\partial p / \partial \vec{n}=0$ ) is paramount to back-propagation of the water-layer reflection energy down to the node position, just after the first arrival. On the other hand, such behavior is not desirable to other boundaries, where their extension is imposed on the maximum range expected for the direct-wave arrival to reach. This measure comes with an associated computational cost, which in turn is mildly attenuated by the interest in relatively small one-way traveltimes (or total trace time). For the numerical solution, a $2^{\text {nd }}$ order finite differences scheme is imposed in both uniformly discretized time and space domains, having a total number of elements sufficient to characterize at least 20 points per wavelength of the central source frequency $\left(45 \mathrm{~Hz}\right.$ ), with the maximum velocity of $c_{\max }=1520 \mathrm{~m} / \mathrm{s}$.

The considered velocity model stands for a $13 \mathrm{~km}$ long section, with $1650 \mathrm{~m}$ deep, having a "Meddie" (Mediterran eddie) of saline waters that out-flow from Mediterranean Sea throughout the Gibraltar Strait over the shelf break in the North Atlantic sea (PAPENBERG et al., 2010). The seismic source is located $8 \mathrm{~m}$ below the surface, with shot intervals being carried at every $50 \mathrm{~m}$. Bottom receivers are deployed at $1650 \mathrm{~m}$ depth, with regularly spaced intervals of $300 \mathrm{~m}$. The total trace-time for each shot recorded is 4.5 $\mathrm{s}$, which are sampled at $10^{-3} \mathrm{~s}$.

In Figure 2, the results are exemplified for a Common Receiver Gather (CRG) obtained at $x=6300 \mathrm{~m}$. Right after the first arrival, several small-amplitude (of order $10^{-5}$ ) transmitted-reflections events, associated with impedance contrasts of the water column, are readily observed.

\section{Interferometric redatum}

The term redatuming refers to the numerical process that moves sources and/or receivers from the acquisition surface to a new, virtual datum plane. Traditionally, this process was carried out with wavefield extrapolation operators, that required previous knowledge of the velocity model where the redatuming takes place (WAPENAAR et al., 2008). However, some interesting alternatives are available, for densely sampled sources and receivers, that can make use of cross-correlation between direct arrivals and observed reflection traveltimes, without previous knowledge of the velocity model. Here we are particularly interested in Fermat's interferometric principle

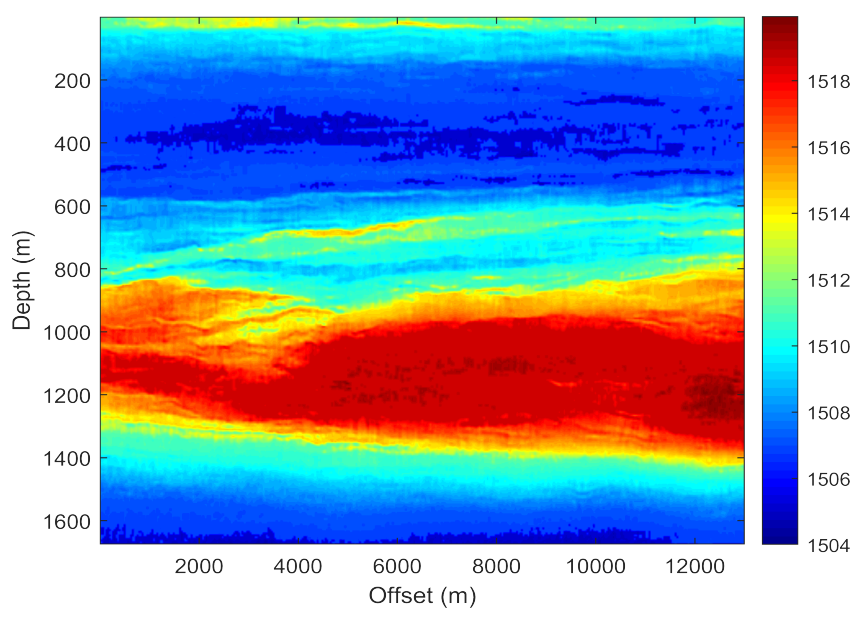

Figure 1: Velocity model for synthetic OBN data. Extracted from PAPENBERG et al. (2010).

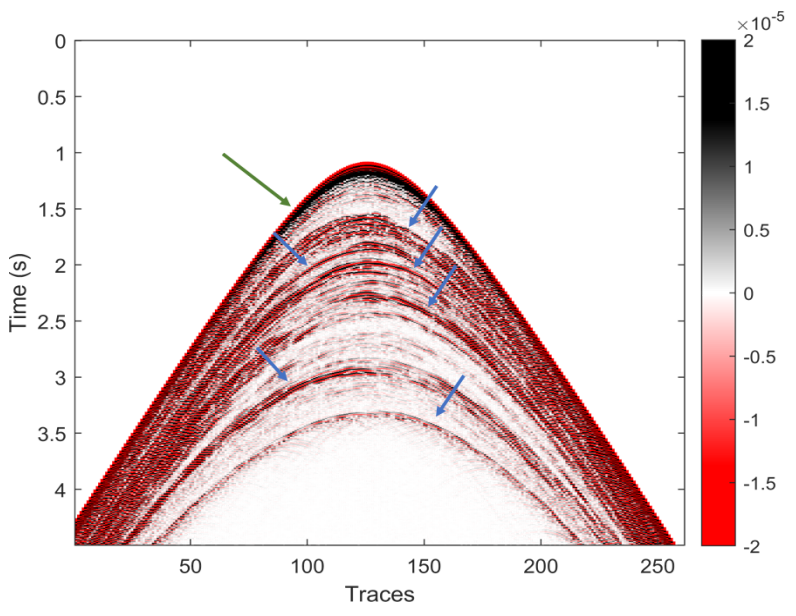

Figure 2: Synthetic common receiver gather obtained at $x=6300 \mathrm{~m}$ position. Direct wave is indicated with the green arrow, and water column reflection events are indicated with blue arrow.

(SCHUSTER, 2005) application to horizontally distributed ocean-bottom receivers, as schematically shown in Figure 3. For that, one must first consider the traveltime $\tau_{s g^{\prime \prime}}$ relation, between a $s$ source and some $g^{\prime \prime}$ OBN-receiver, such as

$$
\tau_{s g^{\prime \prime}}=\tau_{s x}+\tau_{x g}+\tau_{g g^{\prime \prime}}
$$

whereas $\tau_{s x}$ is related to the traveltime between $s$ and $x$ (the location of the layer interface), $\tau_{x g}$ from $x$ to $g$, and $\tau_{g g^{\prime \prime}}$ from $g$ to $g^{\prime \prime}$. The later makes direct reference to first arrivals, which are central to Fermat's interferometric principle. By ascribing fixed $s$ and $g$ positions, it was shown (SCHUSTER, 2005) that a minimization problem can be formulated for the traveltime difference associated to diffraction and specular reflections. A readily available estimation, however, is provided by the direct calculation of the (LHS) difference 


$$
\min _{g^{\prime \prime}}[\overbrace{\tau_{g g^{\prime \prime}}}^{\text {direct wave }}-\overbrace{\tau_{s g^{\prime \prime}}}^{\text {specular mult. }}]=\overbrace{-\tau_{s x}-\tau_{x g}}^{\text {CDP specular primary }},
$$

for all $g^{\prime \prime}$ node positions, which then returns an overall estimation for minimal time difference associated with the Common Depth Point (CDP) specular primary reflection. For a densely distributed source/receiver geometry, a node position can be readily chosen by its proximity to the true minimal, otherwise some interpolation might be considered (specially in more sparsely distributed source/receiver geometry).

\section{Results}

To perform the interferometric redatum, traveltimes associated to direct arrivals and to the reflections events occurring right after their passage, should be picked first in the node data. Although being considerable easier in the case of direct waves, the complexity beneath overlapping events and discontinuities in the water reflections (even in this synthetic data) makes the picking process not entirely straight forward or at least demands a more experienced/trained eye. As an alternative to facilitate this procedure, we here consider the application of a seismic attribute, given by the trace envelope. Apparently, such choice is quite usual in many applications involving marine acoustic equipment, that are adopted in the field of Ocean Acosutic Tomography, for instance (MUNK et al., 2009). Nonetheless, this idea is about to be revisited in the future.

Figure ?? presents obtained results for six water reflection events identified in CRG, with further application of eq. (3). The results display only values taken for a "trusted region", where enough coverage is guaranteed to not influence the Fermat minimum principle, i. e. somewhere near a zerooffset region. Comparisons between the redatum results at zero-offset and a two-way traveltime conversion of the known velocity model, allows a direct association with the identified picked events.

\section{Conclusion}

In this feasibility study we investigated the application of Fermat's interferometric principle to redatum of water reflections traveltimes, which were observed in the downgoing wave field (from a synthetic simulation) to reach ocean-bottom receivers. The obtained results are expected to supply further inversion schemes that are focused on more detailed reconstructions of water velocity models from transmitted OBN data. Their occurrence of such water reflections in the downgoing field of real OBN data are still to be confirmed.

\section{Acknowledgements}

The authors would like to thank André Bulcão and Bruno Dias for the fruitful discussions. This research was supported by Petrobras through "Determinação da velocidade do som da coluna d'àgua utilizando dados de levantamentos sísmicos" project with Universidade Federal of Santa Catarina (UFSC), and ANP through the R\&D levy regulation, process: 2017/00071-6.

\section{References}

BRIGHT, D.; JONES, C., and SELVAGE, J., 2015, Solving water column statics with seismic oceanography: 77th EAGE Conference and Exhibition 2015, 1-5.

CLAERBOUT, J. F., 1968, Synthesis of a layered medium from its acoustic transmission response: Geophysics, 33, 264-269.

DUNN, R. A., 2015, Ocean acoustic reverberation tomography: The Journal of the Acoustical Society of America, 138, 3458-3469.

FER, I.; NANDI, P.; HOLBROOK, W. S.; SCHMITT, R. W., and PÁRAMO, P., 2010, Seismic imaging of a thermohaline staircase in the western tropical North Atlantic: Ocean Science, 6, 621

GRAD, M.; MJELDE, R.; CZUBA, W.; GUTERCH, A.; SCHWEITZER, J., and OTHERS, 2011, Modelling of seafloor multiples observed in OBS data from the North Atlantic-new seismic tool for oceanography?: Polish Polar Research, 32, 375-392.

HOLBROOK, W. S. and FER, I., 2005, Ocean internal wave spectra inferred from seismic reflection transects: Geophysical Research Letters, 32.

KORMANN, J.; COBO, P.; BIESCAS, B.; SALLARÉS, V.; PAPENBERG, C.; RECUERO, M., and CARBONELL, R., 2010, Synthetic modelling of acoustical propagation applied to seismic oceanography experiments: Geophysical Research Letters, 37.

LI, Y.; CHANG, G.; HEWETT, B.; BEAL, E., and YANG, Z., 2015, Detect water velocity variations with direct arrivals and water bottom multiples from $3 d$ subsurface seismic obn/das-vsp: 3rd EAGE Workshop on Borehole Geophysics, $\mathrm{cp}-447$.

MUNK, W.; WORCESTER, P., and WUNSCH, C., 2009, Ocean acoustic tomography: Cambridge university press.

PAPENBERG, C.; KLAESCHEN, D.; KRAHMANN, G., and HOBBS, R. W., 2010, Ocean temperature and salinity inverted from combined hydrographic and seismic data: Geophysical Research Letters, 37.

RICKETT, J. and CLAERBOUT, J., 1999, Acoustic daylight imaging via spectral factorization: Helioseismology and reservoir monitoring: The leading edge, 18, 957-960.

SCHUSTER, G. T., 2005, Fermat's interferometric principle for target-oriented traveltime tomography: Geophysics, 70, U47--U50.

SCHUSTER, G. T.; YU, J.; SHENG, J., and RICKETT, J., 2004, Interferometric/daylight seismic imaging: Geophysical Journal International, 157, 838-852.

WANG, K.; HATCHELL, P.; UDENGAARD, C.; CRAFT, K., and DUNN, S., 2013, Water velocity and tide measurement in marine seismic acquisition: 75th EAGE Conference \& Exhibition incorporating SPE EUROPEC 2013, cp-348.

WAPENAAR, K.; DRAGANOV, D., and ROBERTSSON, J. O. A., 2008, Seismic interferometry: History and present status: Society of Exploration Geophysicists.

WOMBELL, R., 1996, Water velocity variations in 3d seismic processing, in SEG Technical Program Expanded Abstracts 1996, 1666-1669, Society of Exploration Geophysicists.

WRIGHT, J. and COLLING, A., 1995, Seawater: its composition, properties, and behaviour, volume 2: Pergamon. 


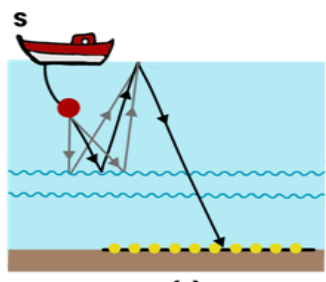

g"(?)
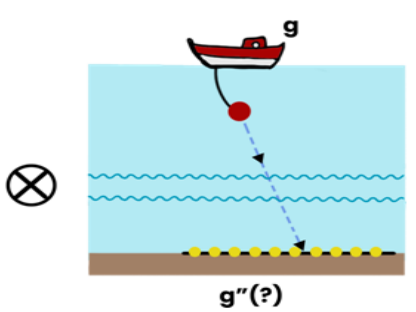

Figure 3: Aligned with redatum idea (CLAERBOUT, 1968; RICKETT and CLAERBOUT, 1999), for a specific node position in $g^{\prime \prime}$, the correlation between $\overline{s g^{\prime}}$ containing the transmitted multiple, with $\overline{g g^{\prime}}$ direct arrival, results in $\overline{s g}$. The resulting information is then similar to a surface reflection acquisition. A Fermat's interferometric principle assumes minor contributions of non-specular reflections to imaging process, justified by high frequency stationary phase analysis (SCHUSTER et al., 2004). On leftmost, the specular ray is present in black color, whereas diffractions variants are displayed in gray.
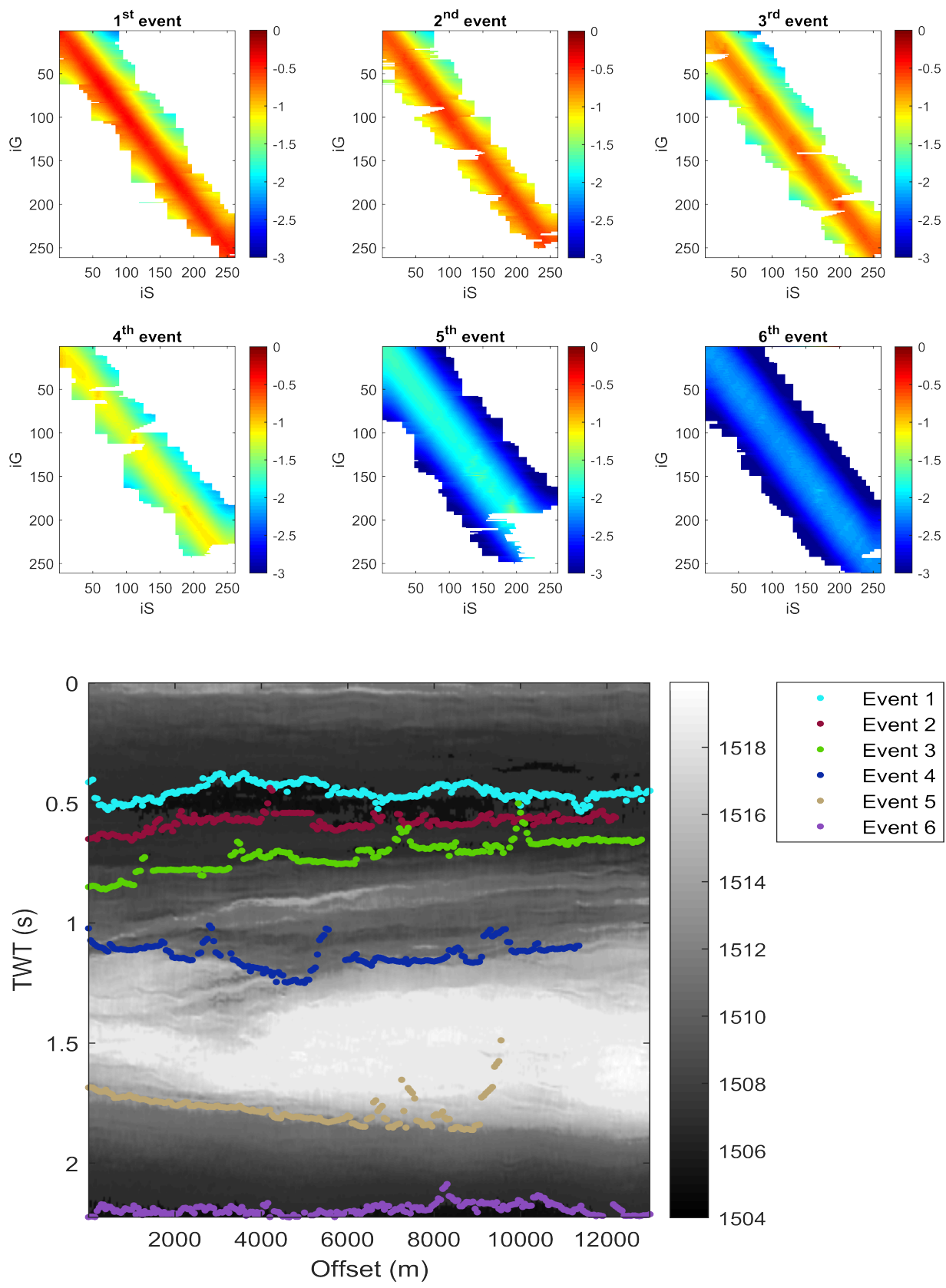

1514

1512

1510

1508

1506

1504

Figure 4: (top) Interferometric traveltimes obtained for six reflection events identified in CRG groups from the synthetic data. (bottom) Obtained zero-offset reflection events overlayed onto the two-way-traveltime water velocity model. 